\title{
Structures and Properties of Ti Alloys after Double Implantation ${ }^{1}$
}

\author{
A.D. Pogrebnjak, S.N. Bratushka, V.V. Uglov**, V.S. Rusakov*, V.M. Beresnev, \\ V.M. Anishchik**, L.V. Malikov, N. Levintant***, and B.P. Gritsenko**** \\ Sumy Institute for Surface Modification, PO BOX 163, Sumy, 40030, Ukraine \\ Tel.: +8(380) 54-78-39, E-mail: apogrebnjak@simp.sumy.ua \\ *Moscow State University, Moscow, Russia \\ **Belarus State University, Minsk, Belarus \\ ***Institute of Fundamental Technological Research PASc, 00-49, Warsaw, Poland \\ ****Institute of Strength Physics and Material Science SB RAS, 2/1, Academichesky ave., Tomsk, 634021, Russia
}

\begin{abstract}
The paper presents new results on investigation of structure and physical-mechanical properties of near surface layers of titanium alloys after $\left(\mathrm{W}^{+}, \mathrm{Mo}^{+}\right)$ion implantation and subsequent thermal annealing under $550^{\circ} \mathrm{C}$ during $2 \mathrm{~h}$. Using back scattering (RBS) of helium ions and protons, scanning electron microscopy (SEM) with microanalysis (EDS), (WDS), proton (ion) induced X-ray emission (PIXE), X-ray phase analysis (ERD) with a sliding beam geometry $\left(0.5^{\circ} \mathrm{C}\right)$, Mössbauer spectroscopy (MS), measurements of nanohardness and elastic modulus, friction wear (cylinder-plate), measurements of corrosion resistance in a salt solution, we investigates VT-6 and VT-22 samples, and determined their fatigue resistance under cyclic loads. Two times increase of the hardness, decrease of wear and increased fatigue resistance was found, which was related to the formation of small dispersion (nanodimension) nitride, carbonitride, and intermetalloid phases.
\end{abstract}

\section{Introduction}

As it is known [1,2], transition of medium energy ions through a solid is accompanied by scattering at matrix atoms and electrons, which results to deceleration and changing of ion motion direction, shifting of crystal atoms from lattice sites, accumulation of impurities in a target, sputtering of material surfaces, atomic mixing, formation of distribution profiles of implanted ions, formation of new phases. This essentially influences their mechanical and chemical properties [1-4].

Application of high-dose and intensive implantation results in shifting of an implanted ion concentration profile in surface vicinity, due to enhancement of a sputtering process $[3,4]$. We understand high-dose and intensive ion implantation (HDIII) as an implantation under which the rate of dose accumulation is about $10^{16} \mathrm{~cm}^{2} / \mathrm{min}$, a concentration of implanted ions is from tens to 100 atomic per cent [5-7], and an ion current density in the target is from units to tens of milliamps under current pulse duration 100 to $200 \mu \mathrm{s}$.
Works [4-5] demonstrated that double implantation of $\mathrm{Cu}^{+}, \mathrm{No}^{+}, \mathrm{Fe}^{+}, \mathrm{Zr}^{+}$into titanium alloys resulted in a change in microhardness, which was, first of all, related to surface layer hardening due to formation of martensite phases, small dispersion carbides and oxycarbides. It had already been published the works $[7,17,18]$ in which they found almost $80 \%$ increase of the fatigue resistance in comparison with initial samples under Hf ion implantation into titanium alloys $[6,7]$. In the middle of the 90th it was demonstrated that $\mathrm{C}, \mathrm{N}, \mathrm{B}$ implantation increased a cyclic life of Ti-6\% Al-4\% (VT-6) alloy by 4-5 times due to deceleration of dislocation motion and a decrease in fracture growth [14]. Also it is known that $\mathrm{W}$ and mo can be applied as doping elements to increase hardness and improve servicing characteristics of construction materials $[12,14,17]$.

In this connection, investigations of high-dose and intensive $\mathrm{W}^{+}$and $\mathrm{Mo}^{+}$ion implantation (HDIII) effects on changes in physical-chemical and mechanical characteristics of titanium alloys VT-6 and VT-22 were of an undoubted interest.

\section{Methods of sample preparation and investigations}

Samples of VT-22 $(\mathrm{Ti}=84 \%, \mathrm{Al} \sim 4.0-5.9 \%, \mathrm{~V} \sim 4.2 \%$, $\mathrm{Fe} \sim 1.2 \%, \mathrm{Mo} \sim 4.0-5.5 \%, \mathrm{Cr} \sim 0.5-2.0 \%)$ and VT-6 (Ti, $\mathrm{Al} \sim 5.5-6.8 \%, \mathrm{~V} \sim 3.5-4.5 \%$ of the mass content), of $15 \times 15 \times 2$ dimensions, polished and annealed to reject residual stresses and cold working, were investigated. Metal ion implantation was performed in the vacuum-arc implantor "DIANA" under $5 \cdot 10^{17} \mathrm{~cm}^{-2}$ dose, $200 \mu$ s pulse duration, the sample surface temperature did exceed $300^{\circ} \mathrm{C}$. Ion implantation was performed in the accelerator chamber under $10^{3} \mathrm{~Pa}$ residual vacuum.

To analyze the element composition of samples we applied the RBS method for helium ions and protons of 2.035 and $2.12 \mathrm{MeV}$ energies, respectively, and a scanning microscopy with microanalysis WDS and an ion-induced X-ray (helium) emission PIXE using the accelerator with an ion beam energy ${ }^{4} \mathrm{He}^{+} \approx 3.1 \mathrm{MeV}$,

\footnotetext{
${ }^{1}$ This work funded by the ISTC project K-1198.
} 
Darmstadt, Germany. The structure and surface relief analysis were performed with the help of a scanning electron microscope REMMA with a microanalyzer WDS (Selmi, Sumy) and EDS.

To investigate the structure of titanium alloys VT-22, we applied a Mössbauer spectroscopy at ${ }^{57} \mathrm{Fe}$ nuclei, a sliding beam in the Wulf-Bregg geometry, additionally performed investigations of nanohardness and microhardness, wear resistance under friction of a cylinder over sample surfaces and measured fatigue resistance under cyclic loads (for some series of samples), using in this specially prepared samples looking like small dumb-bells.

The tests were performed using a three-face Berkovich indentation with a nanohardness measuring device Nano Indenter-II, MTS Systems Corp., Oak Ridge, TN, USA. In the process of testing with a high accuracy a dependence of the indenter top displacement on a load was registered. An accuracy of the print depth measurement was equal to $\pm 0.04 \mathrm{~nm}$, that of the indenter load $- \pm 75 \mathrm{nH}$. The device is able to perform about 3 load and displacement measurements per minute. To decrease vibrations the device was positioned at a vibration isolating table. In every test the indenter was loaded/unloaded three times, each time reaching higher load, which did not exceed $5 \mathrm{mH}$ $(\approx 0.5 \mathrm{~Hz})$ with $150 \mathrm{mH}$ depth.

The tests were performed under constant rate of indentation penetration, which was equal to $5 \mathrm{~nm} / \mathrm{s}$. 5 prints were made in every sample, at $30 \mu \mathrm{m}$ distance. A 30 s stop was made during unloading to measure rate of the indentor body heat expansion. After testing, the hardness was measured according to the indentation print depth, and the elastic modulus was calculated by the unloading curve analysis [20,21].

\section{Results and discussion}

Figure 1 presents the energy spectra of helium ion back scattering with $2.035 \mathrm{MeV}$ energy taken for the samples VT-22 after ion implantation of Mo and W ions with $2 \cdot 10^{17} \mathrm{~cm}^{-2}(a)$ and $5 \cdot 10^{17} \mathrm{~cm}^{-2}(b)$ dose.

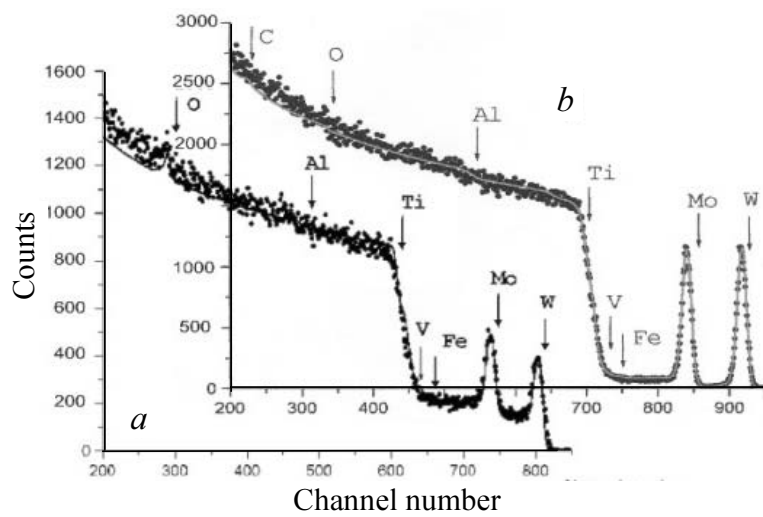

Fig. 1. The energy spectrum of Rutherford back scattering of $\mathrm{He}_{4}$ ions with the energy $E=2.035 \mathrm{MeV}$ taken from a coating surface layer of VT-22 samples (the arrows indicate the element kinematical boundaries) irradiated with $2 \cdot 10^{17} \mathrm{~cm}^{-2}$ dose $(a)$ and $5 \cdot 10^{17} \mathrm{~cm}^{-2}(b)$
One can see that after implantation a wide set of elements: C, O, Al, Ti, V, Fe, Mo, W was found in this sample. Treatment of these spectra according to a standard program allowed us to obtain an element concentration over the surface layers (Table 1).

Table 1. Element concentration from over sample depth for VT-22 with Mo and W $2 \cdot 10^{17} \mathrm{~cm}^{-2}$ dose

\begin{tabular}{|l|c|c|c|c|c|c|c|}
\hline \multirow{2}{*}{ Depth, A } & \multicolumn{7}{|c|}{ Concentration, at \% } \\
\cline { 2 - 8 } & $\mathrm{W}$ & $\mathrm{Mo}$ & $\mathrm{Fe}$ & $\mathrm{V}$ & $\mathrm{Ti}$ & $\mathrm{Al}$ & $\mathrm{O}$ \\
\hline 420.9 & .00 & .00 & 1.01 & 4.08 & 14.35 & 5.29 & 75.27 \\
\hline 819.0 & 4.95 & 12.87 & 1.00 & 4.00 & 43.90 & 5.18 & 28.10 \\
\hline 2366.0 & 2.01 & 2.01 & 1.01 & 4.06 & 85.65 & 5.26 & .00 \\
\hline 3912.9 & 2.01 & 2.01 & 1.01 & 4.06 & 85.65 & 5.26 & .00 \\
\hline 158611.1 & 2.01 & 2.01 & 1.01 & 4.06 & 85.65 & 5.26 & .00 \\
\hline
\end{tabular}

As it is seen from the results presented in the Table, a maximum concentration of $\mathrm{W}$ ions was about 11 at $\%$ and was positioned near their surfaces at about $5 \mathrm{~nm}$ depth, Mo concentration amounting 38 at $\%$ and its maximum was found at $22.4 \mathrm{~nm}$ with $5 \cdot 10^{17} \mathrm{~cm}^{-2}$ dose. Thermal annealing performed for VT-22 samples during $2 \mathrm{~h}$ (at $550^{\circ} \mathrm{C}$ ) resulted in an increase of an ion penetration depth almost by a factor of 1.5. In the calculated partial spectra $P\left(H_{0}\right), P_{\delta}, P_{\varepsilon}$ one can see some differences both in shifts of efficient field values, and in the partial spectra, indicating that as a result of $\mathrm{W}$, Mo ion implantation $\mathrm{Fe}$ atoms penetrated as an impurity in already existing phases (or had been formed in a small quantity), for example, $\mathrm{Al}_{3} \mathrm{Fe}$, in which the iron atoms are in a paramagnetic state or, due to their small dimensions $(<100 \mathrm{~nm})-$ in a supermagnetic state, which indicated a local nonuniformity in the nearest vicinity of the iron atoms corresponding either an amorphous state or a high amount of impurities.

The results of phase analysis performed for VT-22 samples before and after $\mathrm{W}$ and Mo ion implantation demonstrated that the surface layer of VT-22 alloy composed: $\alpha-\mathrm{Ti}, \quad \beta-\mathrm{Ti}, \mathrm{Al}_{3} \mathrm{Ti}$, as well as phases $\mathrm{Al}_{0.6} \mathrm{Cr}_{0.07} \mathrm{Ti}, \mathrm{Al}_{3} \mathrm{Ti}_{0.8} \mathrm{~V}_{0.2}$.

In irradiation by $\mathrm{W}$ and Mo ions the intensity of diffraction lines was redistributed. One should note that basic intensities changes occurred with phases $\mathrm{Al}_{0.67} \mathrm{Cr}_{0.08} \mathrm{Cr}_{0.08}$ and $\mathrm{Al}_{3} \mathrm{Ti}$ (Table 2).

Table 2. Element concentration from over sample depth for VT-22 with Mo and W $5 \cdot 10^{17} \mathrm{~cm}^{-2}$ dose

\begin{tabular}{|c|c|c|c|c|c|c|c|}
\hline \multirow{2}{*}{ Depth, A } & \multicolumn{7}{|c|}{ Concentration, at \% } \\
\cline { 2 - 8 } & $\mathrm{W}$ & $\mathrm{Mo}$ & $\mathrm{Fe}$ & $\mathrm{V}$ & $\mathrm{Ti}$ & $\mathrm{Al}$ & $\mathrm{O}$ \\
\hline 85.2 & 11.06 & .00 & 0.95 & 3.54 & 36.02 & 6.96 & 0.00 \\
\hline 224.3 & 7.80 & 38.44 & 0.95 & 3.62 & 42.67 & 7.24 & 0.00 \\
\hline 364.6 & 0.80 & 12.10 & 1.03 & 3.98 & 59.59 & 8.67 & 13.83 \\
\hline 740.1 & 0.21 & 1.28 & 1.01 & 4.08 & 76.11 & 8.92 & 8.39 \\
\hline 1483.9 & 0.10 & 1.05 & 1.00 & 4.03 & 79.90 & 8.88 & 5.04 \\
\hline 156303.3 & 0.11 & 1.04 & 1.02 & 4.12 & 84.52 & 9.19 & 0.00 \\
\hline
\end{tabular}


In small angle geometry $\left(0.5^{\circ}\right)$, only the lines with gravity centers corresponding to (100) and (101) $\alpha$-Ti in the spectra of initial and treated samples may be distinguished (Fig. 2, b).

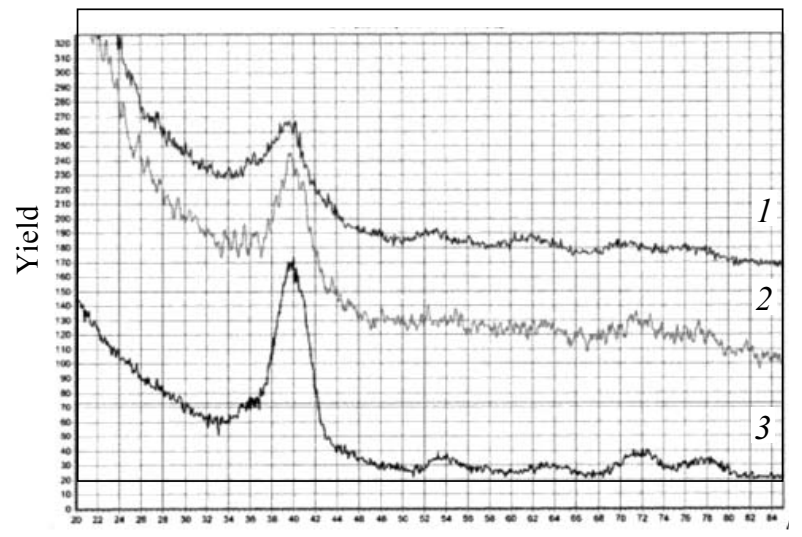

Angle, $2 \theta$

Fig. 2. The diffraction patterns for VT-22 samples for the small angle geometry $(b)$ with the slope angle $0.5^{\circ}$. The lines (100) and (101) $\alpha$-Ti are pronounced: 1 - for an initial state; 2 - VT-22 after W and Mo implantation; 3 - VT-22 after the same implantation with $90 \mathrm{keV}$ energy

Broadening of (101) $\alpha$-Ti line (Table 2) is observed, which indicates a tendency to increased deformation of the $\alpha$-Ti crystal lattice, which was conditioned by Mo and $\mathrm{W}$ implantation (Table 3 ).

Table 3. Element concentration from over sample depth for VT-6 with Mo and W $5 \cdot 10^{17} \mathrm{~cm}^{-2}$ dose

\begin{tabular}{|c|c|c|c|c|c|c|c|}
\hline \multirow{2}{*}{ Depth, A } & \multicolumn{7}{|c|}{ Concentration, at \% } \\
\cline { 2 - 8 } & $\mathrm{W}$ & $\mathrm{Mo}$ & $\mathrm{V}$ & $\mathrm{Ti}$ & $\mathrm{Al}$ & $\mathrm{O}$ & $\mathrm{C}$ \\
\hline 85.2 & 11.06 & .00 & 3.54 & 36.02 & 6.96 & 0.00 & 41.47 \\
\hline 224.3 & 7.08 & 38.44 & 3.62 & 42.67 & 7.24 & 0.00 & 0.00 \\
\hline 364.6 & 0.80 & 12.10 & 3.98 & 59.59 & 8.67 & 13.83 & 0.00 \\
\hline 740.1 & 0.21 & 1.28 & 4.08 & 76.11 & 8.92 & 8.39 & 0.00 \\
\hline 1483.9 & 0.10 & 1.05 & 4.03 & 79.90 & 8.88 & 5.04 & 0.00 \\
\hline 156303.3 & 0.11 & 1.04 & 4.12 & 84.52 & 9.19 & 0.00 & 0.00 \\
\hline
\end{tabular}

The hardness $H$ and the elastic modulus $E$ were determined using nanohardness measuring device (Nanoindenter II) according to the method of Oliver-Pharr [20] and Berkovich indentation.

A value of elastic recovery $W_{e}$ of a surface layer was calculated using the curves "loading-unloading" according to the formula:

$$
W_{e}=\frac{h_{\max }-h_{r}}{h_{\max }},
$$

where $h_{\max }$ is the maximum indentor penetration depth; $h_{r}$ is the residual depth after load relax.

The penetration diagrams are shown in Fig. 3. A peculiarity of the given diagrams is an essentially high for a metal elastic recovery in indentor unloading. This indicates a low modulus of $E$ elasticity with a relatively high hardness $H$ (a value of the elastic recovery was determined by ratio $E / H$ ). A load, which was necessary for indentor penetration to $50 \mathrm{~nm}$ depth was minimum for an initial sample $[(0.8 \pm 0.1) \mathrm{mH}]$, increased to $[(0.9 \pm 0.1) \mathrm{mH}]$ for an implanted sample and was maximum for an implanted sample after annealing $[(1.2 \pm 0.1) \mathrm{mH}]$, Fig. 4 . This indicates the growing hardness of surface layer after implantation and annealing.
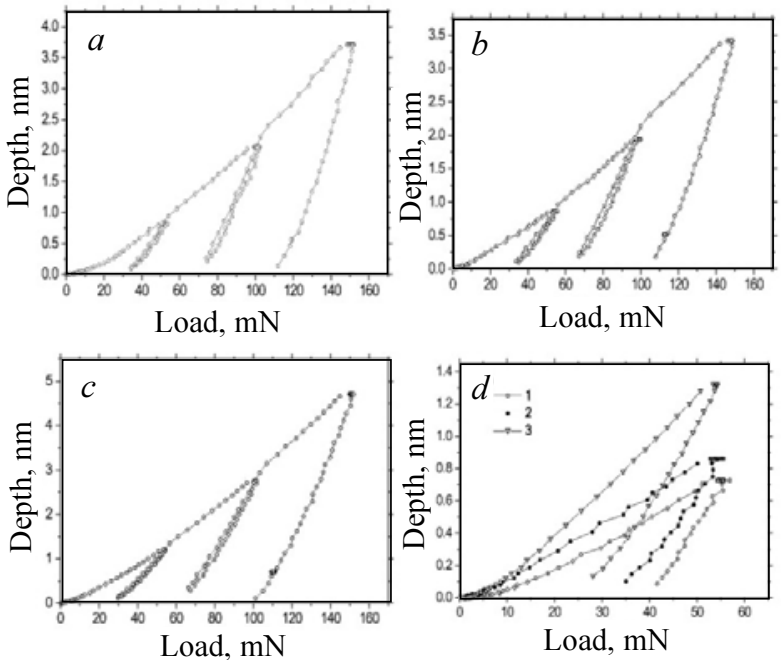

Fig. 3. A diagram of indentation penetration for an initial sample (a), after the implantation (b), after the annealing (c). A first loading cycle to $50 \mathrm{~nm}$ depth $(d): 1-$ for an initial sample; 2 - after the implantation; 3 - the annealing after the implantation

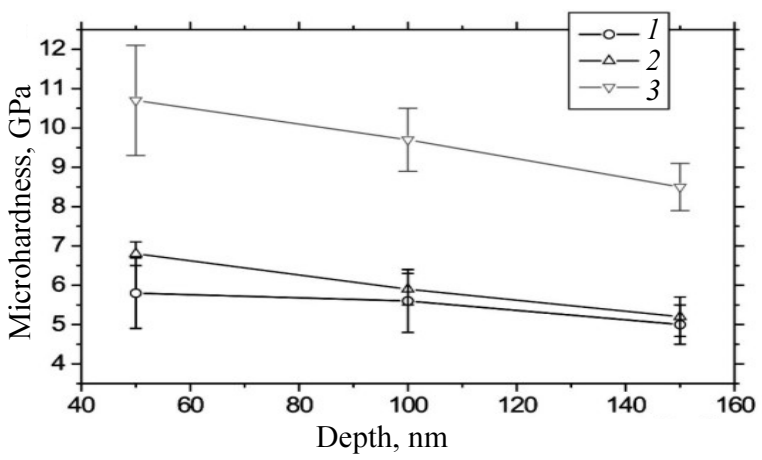

Fig. 4. Hardness vs a depth: 1 - for an initial sample; $2-$ the implantation; 3 - the annealing after the implantation

It is worth our attention the fact that: an elastic recovery of a print depth in unloading after annealing was much longer than that for an initial one.

This indicates that the hardness growth was accompanied by a weak modulus enhancement. I.e., the hardness after implantation and annealing increased more essential than the elastic modulus.

Results for hardness and elastic modulus for 50 , $100,150 \mathrm{~nm}$ print depths are presented in Tables 7 and 8, and the corresponding plot - in Fig. 4.

The initial sample hardness decreased a little with the print depth from 50 to $150 \mathrm{~nm}$. This is a usual scale effect (indentation size effect). The hardness of implanted layer was higher a little, especially at $50 \mathrm{~nm}$ 
depth. Annealing after implantation resulted in a sharp increase of the surface layer hardness, and in comparison with initial material the depth decrease of the hardness occurred more intensively.

Table 4. Result of hardness measurements for titanium alloy VT-22 after ion implantation, GPa

\begin{tabular}{|l|c|c|c|}
\hline Samples & $50 \mathrm{~nm}$ & $100 \mathrm{~nm}$ & $150 \mathrm{~nm}$ \\
\hline Initial & $5.8 \pm 0.8$ & $5.8 \pm 0.5$ & $5.7 \pm 0.7$ \\
\hline After impl. & $10.0 \pm 2.5$ & $8.3 \pm 2.2$ & $7.5 \pm 2.0$ \\
\hline
\end{tabular}

This was an effect of lower situated non-hardened material. Investigation of VT-22 wear resistance in cylinder friction over its surface after double implantation by $\mathrm{W}$ and Mo demonstrated the wear decrease almost by 15 for the first hundreds of friction cycles.

Then the wear became to increase and after 700 cycles reached its initial level. Samples manufactured in the form of dumb-bells were investigated to determine the fatigue resistance within the statistic range 7 to 10 samples per a dependence [23]. After implantation by $\mathrm{W}$ and Mo ions the samples demonstrated an increase in the fatigue resistance by 25 to $30 \%$, and after thermal annealing in vacuum at $550{ }^{\circ} \mathrm{C}$ during $2 \mathrm{~h}$ demonstrated an increase to $60-70 \%$ of their initial value. The phase composition of an implanted sample VT- 6 was the following: $\alpha-\mathrm{Ti}, \beta-\mathrm{Ti}, \mathrm{Al}_{3} \mathrm{Ti}, \mathrm{Al}_{2} \mathrm{Ti}$.

After annealing of the implanted samples basic changes were related to $\mathrm{Al}_{3} \mathrm{Ti}$, in particular, a separated peak (111) $\mathrm{Al}_{3} \mathrm{Ti}$ appeared in the diffraction pattern. Results taken in small angle geometry $\left(0.5^{\circ}\right.$ angle) demonstrates that in the region between $(001)$ and (100) $\alpha$-Ti the emission intensity increased, which seems to be conditioned by additional line (111) $\mathrm{Al}_{3} \mathrm{Ti}$ (Fig. 5, b, Table 5).

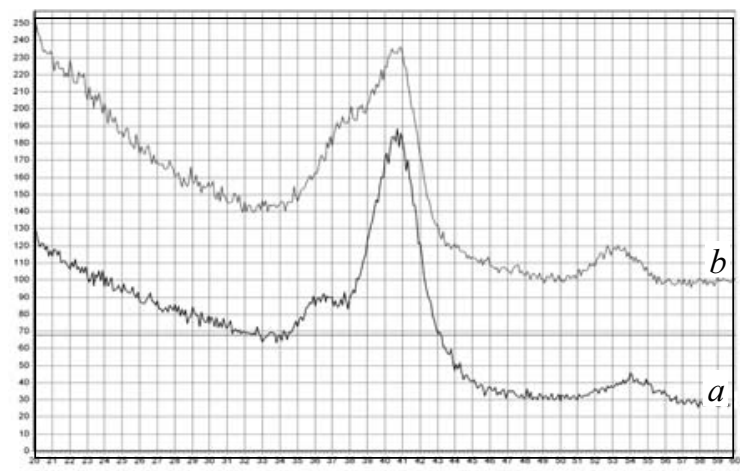

Angle, $2 \theta$

Fig. 5. Diffraction patterns for VT-6 samples after $\mathrm{W}$ and Mo ion implantation with $5 \cdot 10^{17} \mathrm{~cm}^{-2}$ dose, $60 \mathrm{keV}$, after annealing at $550^{\circ} \mathrm{C}$ during $2 \mathrm{~h}(a)$ and taken in a small angle geometry at $0.5^{\circ}$ slope angle in the regions (100) and (101) $\alpha-\mathrm{Ti}$, and additional lines (111) $\mathrm{Al}_{3} \mathrm{Ti}(b)$

Table 5 presents the results of PCA spectra treatment and phase analysis for VT-6 samples.

Figure 6 shows the energy spectra RBS taken for VT-6 samples after double implantation of Mo and W ions for two various doses.
In these spectra one can find $\mathrm{Al}, \mathrm{Ti}, \mathrm{V}, \mathrm{O}, \mathrm{C}$ elements, as well as implanted Mo and $\mathrm{W}$ ions. Table 3 presents the results of element analysis for VT- 6 irradiated with $2 \cdot 10^{17} \mathrm{~cm}^{-2}$ dose over the sample depth, which were taken using a standard program. As it is seen from the Table, a maximum $\mathrm{W}$ concentration reached about 4.44 at $\%$, its maximum occurring at $8.5 \mathrm{~nm}$ depth (for $2 \cdot 10^{17} \mathrm{~cm}^{-2}$ dose). Mo concentration amounted about 11.65 at \% with the maximum at $15.5 \mathrm{~nm}$ depth.

Table 5. Measurement of elastic modules for titanium alloy VT-22 after ion implantation, GPa

\begin{tabular}{|l|c|c|c|}
\hline Samples & $50 \mathrm{~nm}$ & $100 \mathrm{~nm}$ & $150 \mathrm{~nm}$ \\
\hline Initial & $125 \pm 12$ & $129 \pm 16$ & $129 \pm 16$ \\
\hline After impl. & $168 \pm 32$ & $147 \pm 26$ & $148 \pm 34$ \\
\hline
\end{tabular}

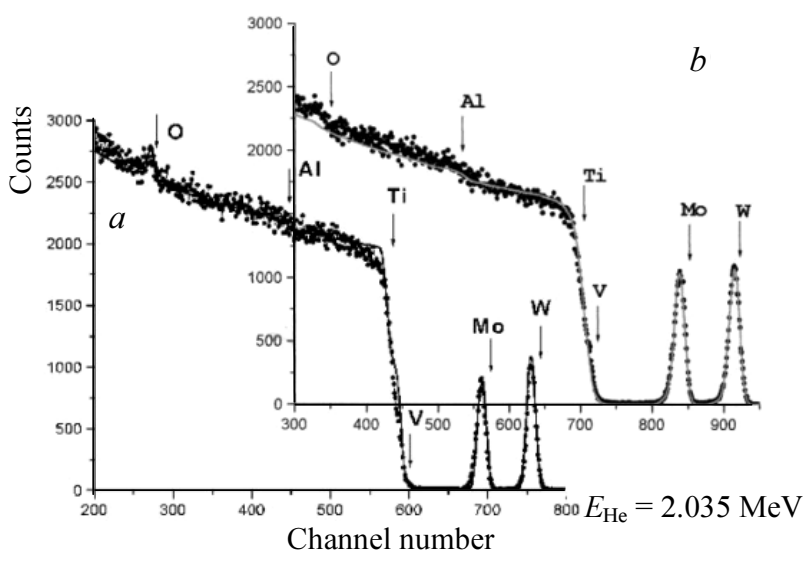

Fig. 6. Energy RBS spectra obtained for VT-6 samples after double $\mathrm{W}$ and Mo ion implantation $(a)$ and after the subsequent annealing at $550{ }^{\circ} \mathrm{C}(b)$

Also V ( 2.91 at \%), Ti (37-87.57 at \%), $\mathrm{Al}(7.15-$ 9.52 at $\%)$ were found. An oxygen peak (16 at \%) occurred at about $23.5 \mathrm{~nm}$, carbon (42.53 at \%) - at $7 \mathrm{~nm}$. When the dose increased to $5 \cdot 10^{17} \mathrm{~cm}^{-2}$, maximum $\mathrm{W}$ concentration reached 11 at $\%$, Mo concentration increased to 38 at \% (see Table 4).

Figure 7 shows $\mathrm{W}$ and mo ion profiles obtained from the RBS energy spectra after implantation with $2 \cdot 10^{17} \mathrm{~cm}^{-2}$ dose and subsequent thermal annealing at $550^{\circ} \mathrm{C}$ during $2 \mathrm{~h}$. The thermal annealing resulted on smearing of the profile, decreasing of the peak $\mathrm{W}$ and Mo concentration.
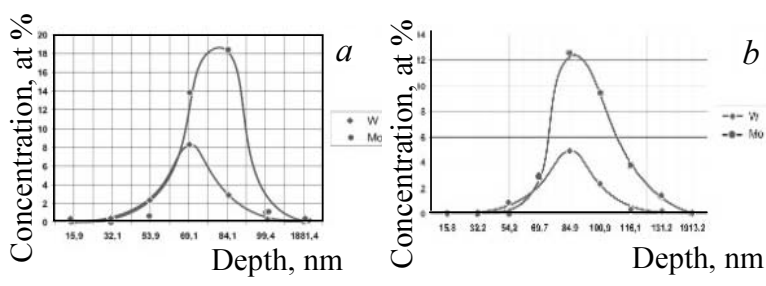

Fig. 7. Profiles of $\mathrm{W}$ and Mo ions obtained after implantation with $2 \cdot 10^{17} \mathrm{~cm}^{-2}$ dose $(a)$ and subsequent thermal annealing in vacuum at $550{ }^{\circ} \mathrm{C}$ temperature during $2 \mathrm{~h}(b)$ 
Calculation of efficient diffusion coefficients for VT-22 samples on the basis of these profiles according to the formula

$$
D_{t}=\frac{\sigma_{i}^{2}-\sigma_{t}^{2}}{2 t}
$$

where $\sigma_{i}^{2}$ is the width of peak $\mathrm{W}$ and Mo concentration at a half height at room temperature; $\sigma_{t}^{2}$ is the width of peak $\mathrm{W}$, Mo concentration at a half height after annealing at $550{ }^{\circ} \mathrm{C}$ during $2 \mathrm{~h} ; t$ is the annealing time, demonstrated that $D_{M o}$ was about $2.8 \cdot 10^{-8} \mathrm{~cm}^{2} / \mathrm{s}$, and for tungsten ions - essentially lower and amounted $D_{W C} 10^{-9} \mathrm{~cm}^{2} / \mathrm{s}$. Evidently, an increased concentration of radiation defects, as well as implantation of $\mathrm{W}$ and Mo impurities resulted in the increased hardness in the near surface layer (almost by 2). In our opinion, this also may be related to oxycarbide formation. I.e., under $\mathrm{W}$ and Mo ion implantation into VT-22 with $2 \cdot 10^{17} \mathrm{~cm}^{-2}$ dose the maximum $\mathrm{W}$ concentration peak was 5 at \% and 11 at $\%$ for Mo. At the same time, a dose increase to $5 \cdot 10^{17} \mathrm{~cm}^{-2}$ enhanced also the maximum $\mathrm{W}$ concentration to (12-14) at \%, and Mo reaching 38 at \%.

Figure 8 and Tables 6,7 present measurement results for nanohardness of VT-6 samples before and after $\mathrm{W}$ and Mo ion implantation (with $2 \cdot 10^{17} \mathrm{~cm}^{-2}$ dose), Tables 6, 7 - those for VT-6 samples. As it is seen from calculation results, the ion implantation resulted in increased hardness (almost by 100\%), especially at $50 \mathrm{~nm}$ depth. And at $150 \mathrm{~nm}$ such increase amounted only about $50 \%$.

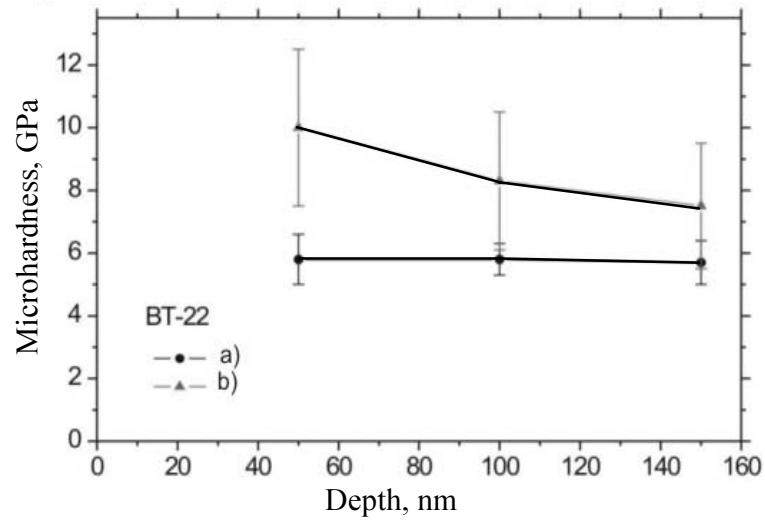

Fig. 8. Nanohardness dependence vs indentation depth in VT-22 samples before $(\bullet)$ and after $(\mathbf{\Delta})$ implantation with $\mathrm{W}$ and Mo ions under $5 \cdot 10^{17} \mathrm{~cm}^{-2}$ dose

Table 6. Result of hardness measurements for titanium alloy VT-6 after ion implantation, GPa

\begin{tabular}{|l|c|c|c|}
\hline \multirow{2}{*}{ Samples } & \multicolumn{3}{|c|}{ Depth, nm } \\
\cline { 2 - 4 } & 50 & 100 & 150 \\
\hline Initial & $5.8 \pm 0.9$ & $5.6 \pm 0.8$ & $5.0 \pm 0.5$ \\
\hline After impl. & $6.8 \pm 0.3$ & $5.9 \pm 0.4$ & $5.2 \pm 0.5$ \\
\hline After annealing & $10.7 \pm 1.4$ & $9.7 \pm 0.8$ & $8.5 \pm 0.6$ \\
\hline
\end{tabular}

The elastic modulus increased also by $45 \%$ for an indentation depth $50 \mathrm{~nm}$, little by little decreasing at 100 and $150 \mathrm{~nm}$ (Tables 6, 7).

Table 7. Measurement of elastic modules for titanium alloy VT-6 after ion implantation, GPa

\begin{tabular}{|l|c|c|c|}
\hline \multirow{2}{*}{ Samples } & \multicolumn{3}{|c|}{ Depth, nm } \\
\cline { 2 - 4 } & 50 & 100 & 150 \\
\hline Initial & $123 \pm 14$ & $124 \pm 21$ & $141 \pm 10$ \\
\hline After impl & $127 \pm 5$ & $120 \pm 5$ & $115 \pm 8$ \\
\hline After annealing & $164 \pm 25$ & $145 \pm 9$ & $140 \pm 7$ \\
\hline
\end{tabular}

\section{Conclusion}

In this work it was demonstrated that the double implantation of Mo and $\mathrm{W}$ ions into titanium alloys VT6 and VT-22 with $5 \cdot 10^{17} \mathrm{~cm}^{-2}$ resulted in formation of concentration profiles with high element concentration at the maximum. Thermal annealing of VT- 6 and VT-22 samples at $550{ }^{\circ} \mathrm{C}$ temperature during $2 \mathrm{~h}$ resulted in the decreased peak Mo and $\mathrm{W}$ concentration and smearing of the element profiles.

Nanohardness measurements demonstrated that maximum hardness change was observed at about $50 \mathrm{~nm}$ depth, at $150 \mathrm{~nm}$ its value being essentially lower. After thermal annealing, an elastic recovery of a print depth in unloading was a little higher than for initial sample, which indicated that the hardness growth was accompanied by a weaker elastic modulus increase.

After implantation and annealing the sample, hardness reached higher values than the elastic modulus for VT-6 samples.

Thermal annealing after Mo and $\mathrm{W}$ ion implantation resulted in a sharp hardness increase of a near surface layer.

The hardness decrease with a depth was more significant in comparison with initial samples, i.e., it seemed to be explained by influence of a lower layer (a nonhardened material).

Results of a phase analysis performed for samples of titanium alloys before and after $\mathrm{Mo}$ and $\mathrm{W}$ ion implantation demonstrated that the VT-22 alloy was composed of: $\alpha$-Ti, $\beta$-Ti, $\mathrm{Al}_{2} \mathrm{Ti}$ and $\mathrm{Al}_{0.6} \mathrm{Cr}_{0.07}$, $\mathrm{Al}_{3} \mathrm{Ti}_{0.8} \mathrm{~V}_{0.2}$. As a result of implantation (irradiation) a redistribution of diffraction lines intensities with phases $\mathrm{Al}_{0.67} \mathrm{Cr}_{0.08} \mathrm{Ti}$ and $\mathrm{Al}_{3} \mathrm{Ti}$ occurred.

A phase composition of $\mathrm{Vt}-6$ was also presented: $\alpha$-Ti, $\beta$-Ti, $\mathrm{Al}_{2} \mathrm{Ti}, \mathrm{Al}_{3} \mathrm{Ti}$. All the changes occurring after annealing of the samples by two types of ions seem to be related to $\mathrm{Al}_{3}$ Ti phase (i.e., the fully separated peak (111) $\mathrm{Al}_{3} \mathrm{Ti}$ ). Simultaneously, in the region (001) and (100) $\alpha$-Ti increased emission intensity was observed, which was conditioned by an additional line (111) $\mathrm{Al}_{3} \mathrm{Ti}$.

$\mathrm{W}$ and Mo ion implantation with $5 \cdot 10^{17} \mathrm{~cm}^{-2}$ dose resulted in increased hardness - almost by $100 \%$ at 
$50 \mathrm{~nm}$ depth and its decrease at $150 \mathrm{~nm}$. An elastic modulus of VT-22 alloy after implantation increased also at low indentation depths $(50 \mathrm{~nm})$ to $50 \%$ and decreased with indentation depth increasing.

\section{Acknowledgments}

The authors are also thankful to A.P. Kobzev (Joint Institute for Nuclear Physics, Dubna, Moscow Red.) for his help in RBS measurements.

\section{References}

[1] J.K. Hirvonen, Ion Implantation in to metals, Moscow, Metallurgiya, 1985, 457 pp.

[2] F.F. Komarov, Ion Implantation in Metalls, Moscow, Energoatomizdat, 1990, 262 pp.

[3] A.D. Pogrebnjak and A.M. Tolopa, Nucl. Instr. and Meth. B 52, 24-43 (1990).

[4] A. Pogrebnjak, A. Kobzev, B.P. Gritsenko et al., J. Appl. Phys. 87, No. 5, 2142-2148 (2000).

[5] A.D. Pogrebnjak, O.G. Bakharev, N.A. Pogrebnjak et al., Phys. Lett. A 265, 225-232. 2000

[6] A.D Pogrebnjak and E.A. Bazyl, Vacuum 64, 1-7 (2002).
[7] V.M. Anischik and V.V. Uglov, Ion Implantation in Tools Steels, Minsk, BGU, 2000, 182 pp.

[8] O.G. Bakharev, A.D. Pogrebnjak, and E.A. Bazyl, Metallofizika and Noveishie Technologies 21/8, 61-70 (1999).

[9] A.I. Meisner, Autoreferat dissertation on Dr. Sc., Tomsk, 2004. 32 pp.

[10] N. Levintant, N.V. Sviridenko, and A.D. Pogrebnjak, Vistnik SumGU 4(76), 93-101 (2005).

[11] E.A, Bazyl, A.D. Pogrebnjak, S.V. Sokolov, and N.V. Sviridenko, FHOM 1, 17-26 (2000).

[12] K.K. Kadyrhanov, F.F. Komarov, A.D. Pogrebnjak et al., Ion Beam and Ion-Plasma Modification of Materials, Moscow, Moscow State Univ., 2005, 640 pp.

[13] M. Mayer, SIMNRA Users Guide Technical Report IPP 9/113 Max-Plank-Institute fur Plasma Physik, Germany, Garching, 1997.

[14] N.A. Azarenkov, V.M. Beresnev, and A.D. Pogrebnjak, Structure and Properties of Coatings and Modified Layers of Materials, Kharkov, Kharkov Nation. Univ., 2007, 565 pp.

[15] M.I. Guseva, Poverhnost' 4, 27-50 (1982).

[16] D.V. Shtanskii, M.I. Petzzhik, I.A. Bashkova et al., Phys. Stat. Sol. 48, 1231-1238 (2006). 